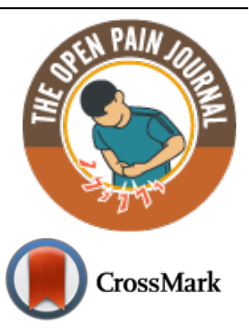

RESEARCH ARTICLE

\title{
Practice of Regional Anesthesia and Its Associated Factors among Anesthesia Professionals Working in Teaching Referral Hospitals of Ethiopia; A Multi- center Study
}

\author{
Elias Habtu ${ }^{1}$, Mamo Nigatu ${ }^{2}$, Yemane Ayele ${ }^{3}$, Mebratu Tila ${ }^{1}$ and Wondu R. Demissie ${ }^{4, *}$ \\ ${ }^{I}$ Department of Anesthesia, College of Health Science, School of Medicine, Wolaita Sodo University, Wolaita Sodo, Ethiopia \\ ${ }^{2}$ Department of Biostatistics and Epidemiology, Institute of Health, Faculty of Public Health, Jimma University, Jimma, Ethiopia \\ ${ }^{3}$ School of Anesthesia, Institute of Health, Faculty of Medical Science, Jimma University, Jimma, Ethiopia \\ ${ }^{4}$ Department of Biomedical Sciences, Institute of Health, Faculty of Medical Science, Jimma University, Jimma, Ethiopia
}

\begin{abstract}
:
Background:

Regional Anesthesia (RA) provides site-specific, complete pain relief, early mobilization, and rehabilitation; and it is preferred than general anesthesia due to associated risks in the later technique. It also ensures prolonged analgesia while reducing the need for systemic drugs with their side effects. Despite these advantages, the techniques have not been embraced as alternatives to general anesthesia in Ethiopia.

Objective:

The study aimed to assess the magnitude of regional anesthesia practice and its associated factors among Anesthesia Care Providers (ACPs) working in Ethiopian teaching referral hospitals, 2019.

\section{Materials and Methods:}

Multi-center-based crossectional study was conducted among all ACPs working in three institutions (Jimma Medical Center, Black Lion hospital and Wolaita Sodo teaching referral hospital) which were randomly selected among six government teaching referral hospitals running postgraduate anesthesia programs; from August 1-September 1, 2019. The practice of RA was considered significant if the participants performed $\geq 5$ types of RA, assuming as minimum representation (30\%) of all types of RA. Data were entered into Epidata manager version 4.3 and exported to SPSS version 22 for further analysis. Logistic regression was applied to determine predictors of RA practice. Adjusted odds ratio and $95 \% \mathrm{CI}$ interval were used to measure the association and P-value $<0.05$ was declared as statistically significant.

Results:

Out of 143 participants, a total of 130 anesthesia professionals participated in the study, making the response rate of $90 \%$. The mean age was $30.77 \pm 7.049$ years that ranges from $22-56$ years. Majority of the respondents were males, $88(67.7 \%)$. About $59.2 \%$ of ACPs practiced RA. The most performed types of RA were spinal anesthesia $(98.5 \%)$, caudal anesthesia $(72.3 \%)$ and axillary block $(69.2 \%)$, while sub gluteal sciatic block and IV RA were the least practiced types of RA ( $8.5 \%$ each). Finally, two variables (years of experience (1-5 years) and academic qualification (above MSc)) were identified as the independent predictors of RA practice among ACPs with AOR of 6(1.7-21.6), $\mathrm{p}-\mathrm{v}=0.005$ and 10.4(1.9-56.9), $\mathrm{p}-\mathrm{v}=0.007$ respectively.

Conclusion:

In a nutshell, the practice of RA in teaching government hospitals of Ethiopia was relatively low despite some RA types like SA were almost practiced well. Thus, ACPs were expected to practice all types of RA than routinely abusing GA for patient safety and welfare in all dimensions.
\end{abstract}

Keywords: Regional anesthesia practice, Teaching institutions, Epidural Anesthesia, Anesthesia care providers, Associated factors, Caudal anesthesia.

\begin{tabular}{ll|l|l} 
Article History & Received: August 25, 2020 & Revised: January 7, 2021 & Accepted: February 11, 2021
\end{tabular}

\section{INTRODUCTION}

Regional Anesthesia (RA) refers to applying anesthetics to a specific area without causing general loss of consciousness, which has become important for pain and surgical management 
if performed by an anesthesiologist who possesses the competence and skills. Types of regional anesthesia can be categorized as neuraxial anesthesia (Spinal Anesthesia (SA), Epidural Anesthesia (EA) and Caudal Anesthesia (CA)) and Peripheral Nerve Blocks (PNB) [1, 2].

RA is often used for different types of surgeries like orthopedic surgery, gynecological/obstetrics surgery, day case and ambulatory surgeries, removal of an enlarged prostate, and the current studies recommended the practice of RA even in laparoscopic surgery [3 - 6].

The use of regional techniques provides site-specific, complete pain relief, facilitates early mobilization and rehabilitation while avoiding General Anesthesia (GA) and associated risks of other techniques. It also ensures prolonged analgesia while reducing the need for systemic drugs with their side effects. RA has a good safety profile, can be used in all age groups (for instance, in pediatrics, caudal anesthesia seems to be an inexpensive, simple, and effective technique not only as a supplement for postoperative analgesia, but also as a single method of anesthesia in providing excellent postoperative analgesia) [7].

RA is also recommended in the battle field as military medicine over GA for different reasons (excellent operating conditions, profound perioperative analgesia, hemodynamic stability, limb-specific anesthesia, reduced need for other anesthetics, reduced or eliminated use of narcotics, improved postoperative alertness, minimal adverse effects, rapid recovery from anesthesia and cost-effectiveness) [8 - 10].

The newer Local Anesthetic (LA) agents have improved the safety and efficacy of RA. Additionally, the avoidance of opioids with regional techniques can be a distinct advantage in the day surgery setting. RA has the potential to produce highquality analgesia with minimum morbidity compared to the other modalities of postoperative pain management $[7,11]$.

In general, RA is recommended if surgery is indicated over GA in terms of risk of aspiration, difficult airway, postoperative pain, nausea, vomiting, awaking time, hospital stay, costs, risk of Deep Venous Thrombosis (DVT), volume of blood loss and specific side effects of multi drug used, the incidence of postoperative chest infection, postoperative oxygenation and stress response to surgery $[12,13]$. Thus, the use of regional blocks in modern anesthesiology has increased in the last two decades for their advantages [14]. But, it has not been implemented well in our country yet, as majority of anesthesia professionals are routinely abusing GA.

There are numerous potential explanations for differences or associated factors in RA practice, including patient characteristics (racial/ethnic, age and gender), differences in health insurance, geographical proximity to care, or insufficient literacy and knowledge, hospital policies and patient and physician preferences, disparities in the use of health-care resources [15]. Previous studies revealed that the perception of adequate training, nerve block rotation, adequate application in

\footnotetext{
* Address correspondence to this author at Department of Biomedical Sciences, Jimma University, Institute of Health, Faculty of Medical Science, Jimma, Ethiopia; P.O.Box 378; Tel: +251-471111457; Fax: +251471111450;

E-mail: majore04@gmail.com; wondu.demissie@ju.edu.et
}

education, following innovations were the factors that significantly affect the RA practice [16 - 21].

Despite extensive literatures on the potential benefits of RA, there are sparse evidence-based data to evaluate the frequency of RA practice at the national or international level. Regardless of their benefits as compared to other forms of anesthesia, it is infrequently used (61\%) and it has not been embraced as an alternative to GA in Ethiopia. Moerover, there are limited studies that revealed the magnitude of RA practice and associated factors in Ethiopia [22]. Thus, the present study aimed to assess the magnitude of RA practice and its associated factors among anesthesia professionals.

\section{METHODS}

The study was conducted among anesthesia professionals in Ethiopian government teaching referral hospitals (Jimma Medical Center (JMC), Black Lion Hospital (BLH) and Wolaita Sodo Hospital (WSH)). A multi- center-based crossectional study design was employed among sampled 143 ACPs.

The study was conducted by self-administered questionnaires that were prepared in English. Data were entered into Epidata manager version 4.3 and exported to SPSS version 20 for further statistical analysis. Descriptive statistics like measures of central tendency (mean, median and mode) and frequency were used. In bivariate analysis, cross-tabulation and binary logistic regression were conducted to explore the association between covariates and outcome variable. Those variables with $p$-value $<0.25$ were taken as a candidate for the final model. Multivariable logistic regression was used to identify independent predictors of RA practice among ACPs. In multivariate analysis, an Adjusted Odds Ratio (AOR) with 95\% Confidence Interval (CI) was used to assess the association between the outcome variable (RA practice) and the associated factors, and a p-value of $<0.05$ was declared as a statistical significance.

Implementation of the proposal was carried out after getting an approval letter from the ethical clearance committee/ethical review board of Jimma University. An official letter of collaboration and permission request to conduct the study was obtained from the Department of Anesthesia. Informed verbal and written consent was taken from the respondents/clients after explaining the objectives and purpose of the study. The participants were assured that they have full right to participate or withdraw from the study and the collected data/ information will be kept confidential.

\subsection{Operational Definitions}

RA Practice- was considered significant if the participants performed $\geq 5$ types of RA assuming as minimum representation $(30 \%)$ of types of RA.

Knowledge- The anesthesia professionals were considered to have knowledge if their score was $>10$ on knowledge related questions about RA.

Attitude- The anesthesia professionals were considered to have the right attitude if they scored $>10$ score on attituderelated questions about RA. 


\section{RESULTS}

\subsection{Socio-demographic Characteristics of Study} Participants

From 143 anesthesia professionals sampled to enroll in the study, about 130 ACPs participated, making the response rate of $90 \%$. The mean age was $30.77 \pm 7.049$ years that ranges from
22-56 years. Majority of the participants were males $(67.7 \%)$ (Table 1).

\subsection{Regional Anesthesia Practice Status of Anesthesia Care Providers}

The practice of RA among ACPs was $59.2 \%$ who performed $\geq 5$ types of RA (Fig. 1)

Table 1. Socio- demographic characteristics of Anesthesia care providers, 2019.

\begin{tabular}{|c|c|c|c|}
\hline Variables & Categories & Frequency & Percentage $(\%)$ \\
\hline \multirow[t]{5}{*}{ Age in years } & $\leq 30$ & 86 & 66.2 \\
\hline & $31-40$ & 32 & 24.6 \\
\hline & $41-50$ & 9 & 6.9 \\
\hline & $>50$ & 3 & 2.3 \\
\hline & Total & 130 & 100.0 \\
\hline \multirow[t]{3}{*}{ Sex } & Male & 88 & 67.7 \\
\hline & Female & 42 & 32.3 \\
\hline & Total & 130 & 100.0 \\
\hline \multirow[t]{6}{*}{ Academic Qualification } & $\mathrm{BSc}$ & 47 & 36.2 \\
\hline & MSc student & 32 & 24.6 \\
\hline & $\mathrm{MSc}$ & 21 & 16.2 \\
\hline & Resident & 21 & 16.2 \\
\hline & Anesthesiologist & 9 & 6.9 \\
\hline & Total & 130 & 100.0 \\
\hline \multirow[t]{5}{*}{ Year of experience } & $\leq 1$ & 20 & 15.4 \\
\hline & $1-5$ & 70 & 53.8 \\
\hline & $5-10$ & 32 & 24.6 \\
\hline & $>10$ & 8 & 6.2 \\
\hline & Total & 130 & 100.0 \\
\hline \multirow[t]{4}{*}{ Institution } & $\mathrm{JMC}$ & 38 & 29.2 \\
\hline & BLH & 64 & 49.2 \\
\hline & WSH & 28 & 21.5 \\
\hline & Total & 130 & 100.0 \\
\hline
\end{tabular}

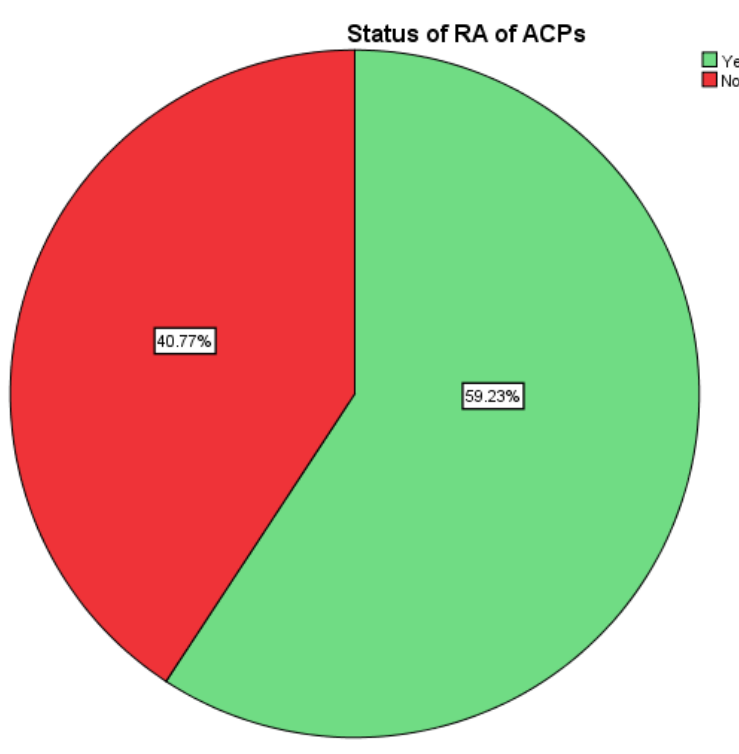

Fig. (1). Regional anesthesia practice status of Anesthesia care providers, 2019. 
The most performed types of RA were SA $(98.5 \%)$, CA (72.3\%) and axillary block (69.2\%), while Sub gluteal sciatic block and IV RA were the least used ( $8.5 \%$ each) types RA (Table 2).
When the numbers of RA performed were analyzed, a few respondents $(1.5 \%)$ did not perform any type of RA while the majorities $(46.9 \%)$ were observed to perform 1-5 types of RA (Fig. 2).

Table 2. Frequency of practiced types of RA.

\begin{tabular}{|c|c|c|c|}
\hline RA types & Categories & Frequency & Percentage (\%) \\
\hline \multirow[t]{3}{*}{ Spinal anesthesia } & Yes & 128 & 98.5 \\
\hline & No & 2 & 1.5 \\
\hline & Total & 130 & 100.0 \\
\hline \multirow[t]{3}{*}{ Epidural anesthesia } & Yes & 55 & 42.3 \\
\hline & No & 75 & 57.7 \\
\hline & Total & 130 & 100.0 \\
\hline \multirow[t]{3}{*}{ Caudal anesthesia } & Yes & 94 & 72.3 \\
\hline & No & 36 & 27.7 \\
\hline & Total & 130 & 100.0 \\
\hline \multirow[t]{3}{*}{ Interscalene block } & Yes & 32 & 24.6 \\
\hline & No & 98 & 75.4 \\
\hline & Total & 130 & 100.0 \\
\hline \multirow[t]{3}{*}{ Supraclavicular block } & Yes & 51 & 39.2 \\
\hline & No & 79 & 60.8 \\
\hline & Total & 130 & 100.0 \\
\hline \multirow[t]{3}{*}{ Infraclavicular block } & Yes & 20 & 15.4 \\
\hline & No & 110 & 84.6 \\
\hline & Total & 130 & 100.0 \\
\hline \multirow[t]{3}{*}{ Axillary block } & Yes & 90 & 69.2 \\
\hline & No & 40 & 30.8 \\
\hline & Total & 130 & 100.0 \\
\hline \multirow[t]{3}{*}{ Elbow block } & Yes & 30 & 23.1 \\
\hline & No & 100 & 76.9 \\
\hline & Total & 130 & 100.0 \\
\hline \multirow[t]{3}{*}{ Lumbar plexus block } & Yes & 15 & 11.5 \\
\hline & No & 115 & 88.5 \\
\hline & Total & 130 & 100.0 \\
\hline \multirow[t]{3}{*}{ Femoral block } & Yes & 52 & 40.0 \\
\hline & No & 78 & 60.0 \\
\hline & Total & 130 & 100.0 \\
\hline \multirow[t]{3}{*}{ Saphenous block } & Yes & 32 & 24.6 \\
\hline & No & 98 & 75.4 \\
\hline & Total & 130 & 100.0 \\
\hline \multirow[t]{3}{*}{ Classic sciatic block } & Yes & 19 & 14.65 \\
\hline & No & 111 & 85.4 \\
\hline & Total & 130 & 100.0 \\
\hline \multirow[t]{3}{*}{ Sub gluteal sciatic block } & Yes & 11 & 8.5 \\
\hline & No & 119 & 91.5 \\
\hline & Total & 130 & 100.0 \\
\hline \multirow[t]{3}{*}{ Popliteal block } & Yes & 35 & 26.9 \\
\hline & No & 95 & 73.1 \\
\hline & Total & 130 & 100.0 \\
\hline \multirow[t]{3}{*}{ Ankle block } & Yes & 63 & 48.5 \\
\hline & No & 67 & 51.5 \\
\hline & Total & 130 & 100.0 \\
\hline
\end{tabular}


(Table $\square$ ) contd......

\begin{tabular}{|c|c|c|c|}
\hline RA types & Categories & Frequency & Percentage $(\%)$ \\
\hline \multirow[t]{3}{*}{ Thoracic paravertebral block } & Yes & 46 & 35.4 \\
\hline & No & 84 & 64.6 \\
\hline & Total & 130 & 100.0 \\
\hline \multirow[t]{3}{*}{ Transverse abdominis plane block } & Yes & 77 & 59.2 \\
\hline & No & 53 & 40.8 \\
\hline & Total & 130 & 100.0 \\
\hline \multirow[t]{3}{*}{ IV RA } & Yes & 11 & 8.5 \\
\hline & No & 119 & 91.5 \\
\hline & Total & 130 & 100.0 \\
\hline \multirow[t]{3}{*}{ Other } & Yes & 38 & 29.2 \\
\hline & No & 92 & 70.8 \\
\hline & Total & 130 & 100.0 \\
\hline
\end{tabular}

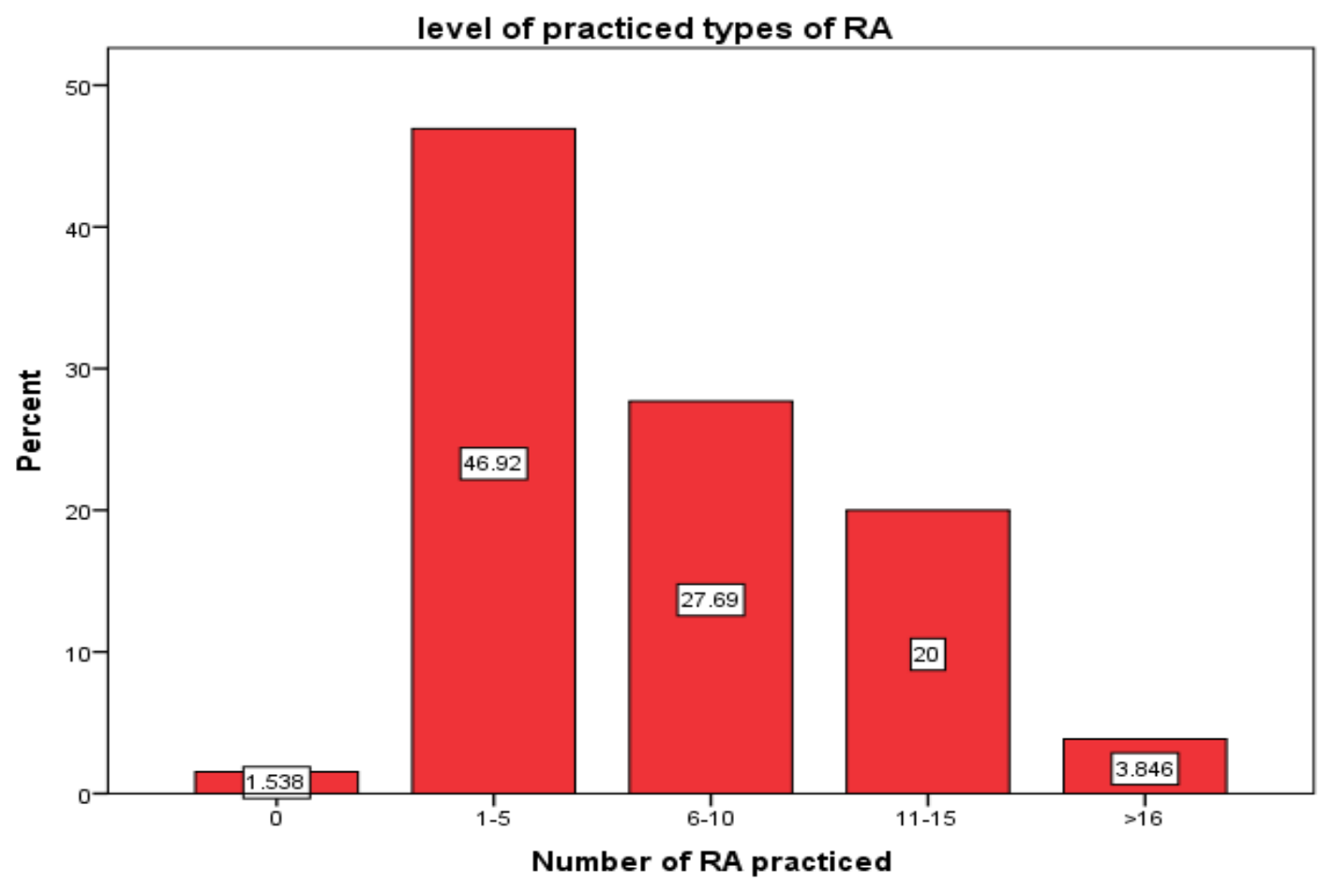

Fig. (2). Frequency of number of RA practiced among ACPs, 2019.

\subsection{Factors Associated with the Practice of RA}

To identify factors associated with the practice of RA, cross-tabulation and logistic regression analysis were applied. In the bivariate analysis, the candidate variables having a pvalue $<0.25$ were selected for the final model. Accordingly, about eight variables (age, sex. experience, professional qualification, institution, knowledge concerning RA and attitude towards RA) were identified as the expected factors associated with the practice of RA with their specific COR, 95\% CI and p-values as explained in Table $\mathbf{3}$ in detail.

Further, multivariate analysis (binary logistic regression with 'enter' methods) was used to identify the main predictor variables. Finally, two variables (years of experience, professional qualification) were identified as factors associated with the practice of RA among ACPs with a p-value less than 0.05 and specific AOR (95\% CI).

The possible interpretation was forwarded as MSc and specialty holders reported to have practiced RA 10.4 times more likely compared with ACPs who had other qualifications [AOR of 10.4(1.9-56.9), $\mathrm{p}=0.007$ ].

There was also a statistically significant difference among ACPs regarding years of experiences in practicing RA; those with experience of 1-5 years were 6 times more likely to practice RA than those with the experience of $\leq 1$ year $[$ AOR of 6(1.7-21.6), $\mathrm{p}=0.005]$ (Table 4). 
Table 3. Results of bivariate analysis of the practice of regional anesthesia among ACPs, 2019.

\begin{tabular}{|c|c|c|c|c|}
\hline Variables & Practiced No (\%) & Not practiced No (\%) & $\operatorname{COR}(95 \% \mathrm{CI})$ & $P$-value \\
\hline $\begin{array}{l}\text { Age: } \\
\leq 30\end{array}$ & $44(33.8)$ & $42(32.3)$ & 1 & - \\
\hline $31-40$ & $26(20)$ & $6(4.6)$ & $4.1(1.5-11)$ & $0.005^{*}$ \\
\hline$\geq 41$ & $7(5.4)$ & $5(3.8)$ & $1.3(0.4-4.5)$ & 0.642 \\
\hline Sex: Male & $57(43.8)$ & $31(23.8)$ & $2.02(0.95-4.2)$ & $0.065^{*}$ \\
\hline Female & $20(15.4)$ & $22(16.9)$ & 1 & - \\
\hline $\begin{array}{c}\text { Qualification: } \\
\text { BSc, MSc students and residents }\end{array}$ & $49(37.7)$ & $51(39.2)$ & 1 & - \\
\hline MSc holders and Anesthesiologists & $28(21.5)$ & $2(1.5)$ & $14.5(3.3-64.4)$ & $0.000^{*}$ \\
\hline $\begin{array}{c}\text { Experience: } \\
\leq 1\end{array}$ & $4(3.1)$ & $16(12.3)$ & 1 & - \\
\hline $1-5$ & $44(33.8)$ & $26(20)$ & $6.7(2.0-22.4)$ & $0.002 *$ \\
\hline$\geq 6$ & $29(22.3)$ & $11(8.5)$ & $10.5(2.9-38.6)$ & $0.000^{*}$ \\
\hline $\begin{array}{l}\text { Institution: } \\
\text { JMC }\end{array}$ & $19(14.6)$ & 19(14.6) & 1 & - \\
\hline $\mathrm{BLH}$ & $43(33.1)$ & $21(16.2)$ & $2(0.9-4.6)$ & $0.088^{*}$ \\
\hline WSH & $15(11.5)$ & $13(10)$ & $1.2(0.4-3)$ & 0.774 \\
\hline $\begin{array}{l}\text { Knowledge: } \\
\text { Yes }\end{array}$ & $75(57.7)$ & $44(33.8)$ & $7.6(1.5-37.1)$ & $0.011^{*}$ \\
\hline No & $2(1.5)$ & $9(6.9)$ & 1 & - \\
\hline $\begin{array}{l}\text { Attitude: } \\
\text { Yes } \\
\end{array}$ & $76(58.5)$ & $47(36.2)$ & $9.7(1.1-83.1)$ & 0.038* \\
\hline No & $1(0.8)$ & $6(4.6)$ & 1 & - \\
\hline
\end{tabular}

*: statistically significant

Table 4. Results of multivariate analysis of regional anesthesia practice among ACPs, 2019.

\begin{tabular}{|c|c|c|c|c|}
\hline Variables & Practiced No (\%) & Not practiced No (\%) & $\operatorname{AOR}(95 \% \mathrm{CI})$ & $P$-value \\
\hline $\begin{array}{c}\text { Qualification: } \\
\text { BSc, MSc students and residents }\end{array}$ & $49(37.7)$ & $51(39.2)$ & 1 & \\
\hline MSc holders and Anesthesiologists & $28(21.5)$ & $2(1.5)$ & $10.4(1.9-56.9)$ & $0.007 *$ \\
\hline $\begin{array}{l}\text { Experience: } \\
\leq 1\end{array}$ & $4(3.1)$ & $16(12.3)$ & 1 & \\
\hline $1-5$ & $44(33.8)$ & $26(20)$ & $6(1.7-21.6)$ & $0.005 *$ \\
\hline$\geq 6$ & $29(22.3)$ & $11(8.5)$ & $3.2(0.67-14.7)$ & 0.143 \\
\hline
\end{tabular}

*: statistically significant

\section{DISCUSSION}

Since the scope of RA is vast, the present study classified RA practices in different types (about 19) and assessed the magnitude of RA practices among ACPs working in three institutions. The mean of RA practice was $6.8 \pm 4.7 \mathrm{SD}$ that ranges from $0-18$. The study showed that only $1.5 \%$ of the respondents did not perform any type of RA, yet the majority of the respondents $(98.5 \%)$ performed at least 1 type of RA. This finding was against a study conducted by Haile et al. [22], who reported $39 \%$ of respondents who did not perform any type of RA. The possible difference might be due to the short period of study time ( 2 months), and they studied non-teaching hospitals; this may decrease RA practice.

About $17.7 \%$ of respondents in the present study did not perform any type of peripheral nerve block, which is in harmony with the findings of Mwangi [23], who reported that $26.7 \%$ of respondents did not perform any type of peripheral nerve block in Kenya.
The magnitude of RA practice was varied among different types. The most performed practices were SA $(98.5 \%)$, CA (72.3\%) and axillary block (69.3\%), while sub gluteal sciatic block and IV RA were the least practiced types of RA ( $8.5 \%$ each). This pattern of RA practice was also supported by studies of Buist [24] (who reported that SA was most frequently performed (98\%)) and Hadzic et al. [25], (who revealed that most anesthesiologists $(97.8 \%)$ perform at least some regional anesthesia techniques (any regional anesthesia technique).

About $46.9 \%$ of respondents practiced 1-5 types of RA, $27.6 \%$ performed $6-10$ types of RA, $20 \%$ performed $11-15$ types of RA and only a few (3.8\%) performed $>16$ types of RA. The present finding was in harmony with the study done in the USA by Hadzic et al. [5], and in Kenya by Mwangi [23], who reported the practice of $<5$ types of RA being $50.5 \%$ and $43.1 \%$, respectively.

The present study deliberately used $\geq 5$ types of RA which is the minimum (30\%) representation of RA from listed 19 
types based on the previous study of Hadzic et al. [25]. Accordingly, $59.2 \%$ of respondents had practiced $\geq 5$ types of RA while the remaining $40.8 \%$ didn't practice RA. This finding was against the study conducted by Mwangi [23], who revealed that only $29.2 \%$ of the respondents practiced $\geq 5$ types of RA. This difference might be due to their short study period (2 months) and they included only PNB.

Finally, two independent predictors (academic qualification, year of experience) were identified as factors associated with the status of RA practice in harmony with the study of Haile et al. [22], who revealed that academic qualification of the ACPs and their years of experience have shown a significant association with the wide practice of RA.

\section{CONCLUSION AND RECOMMENDATION}

In a nutshell, the practice of RA in teaching government hospitals of Ethiopia was relatively low despite some RA types (spinal anesthesia which was $100 \%$ practiced). Thus, ACPs were expected to practice all types of RA in reference to routinely abusing GA for patient safety and welfare in all dimensions. The current study also revealed that the qualification and experience of ACPs were associated with the practice of RA and the authors recommend the professionals to enhance their qualification to deliver different RA techniques routinely.

\section{ETHICS APPROVAL AND CONSENT TO PARTI- CIPATE}

Ethical clearance was obtained from Jimma University Review Board (JU/IRB/15/11/2019) and a letter of cooperation was obtained from Department of Anesthesia, Jimma University, Ethiopia.

\section{HUMAN AND ANIMAL RIGHTS}

No animals were used in this research. All human research procedures followed were in accordance with the ethical standards of the committee responsible for human experimentation (institutional and national), and with the Helsinki Declaration of 1975, as revised in 2013.

\section{CONSENT FOR PUBLICATION}

Informed verbal and written consent was taken from each participants after explaining the objectives and purpose of the data collection.

\section{AVAILABILITY OF DATA AND MATERIALS}

The data supporting the findings of the article will be made available upon reasonable request to the corresponding author [W. D.] .

\section{FUNDING}

This study was funded by Jimma University, Ethiopia.

\section{CONFLICT OF INTEREST}

The authors declare no conflict of interest, financial or otherwise.

\section{ACKNOWLEDGEMENTS}

The authors would like to thank Jimma University for providing funding, and all data collectors and the drivers participated in the study.

\section{REFERENCES}

[1] Carli F, Kehlet H, Baldini G, et al. Evidence basis for regional anesthesia in multidisciplinary fast-track surgical care pathways. Reg Anesth Pain Med 2011; 36(1): 63-72.

[http://dx.doi.org/10.1097/AAP.0b013e31820307f7] [PMID: 22002193]

[2] American Society of Anesthesiologists (ASA). Statement on Regional Anesthesia 2017. Available from: https://www.asahq.org/standardsand-guidelines/statement-on-regional-anesthesia

[3] Liu SS, Strodtbeck WM, Richman JM, Wu CL. A comparison of regional versus general anesthesia for ambulatory anesthesia: a metaanalysis of randomized controlled trials. Anesth Analg 2005; 101(6): 1634-42.

[http://dx.doi.org/10.1213/01.ANE.0000180829.70036.4F] [PMID: 16301234]

[4] Rawal N. Analgesia for day-case surgery. Br J Anaesth 2001; 87(1): 73-87.

[http://dx.doi.org/10.1093/bja/87.1.73] [PMID: 11460815]

[5] Hadzic A, Karaca PE, Hobeika P, et al. Peripheral nerve blocks result in superior recovery profile compared with general anesthesia in outpatient knee arthroscopy. Anesth Analg 2005; 100(4): 976-81. [http://dx.doi.org/10.1213/01.ANE.0000150944.95158.B9] [PMID: 15781509]

[6] Visoiu M, Joy LN, Grudziak JS, Chelly JE. The effectiveness of ambulatory continuous peripheral nerve blocks for postoperative pain management in children and adolescents. Paediatr Anaesth 2014; 24(11): 1141-8.

[http://dx.doi.org/10.1111/pan.12518] [PMID: 25176318]

[7] Moores A, Fairgrieve R. Regional anaesthesia in paediatric practice. Curr Anaesth Crit Care 2004; 15: 284-93.

[http://dx.doi.org/10.1016/j.cacc.2004.08.013]

[8] Aldington DJ, McQuay HJ, Moore RA. End-to-end military pain management. Philos Trans R Soc Lond B Biol Sci 2011; 366(1562): 268-75.

[http://dx.doi.org/10.1098/rstb.2010.0214] [PMID: 21149362]

[9] Buckenmaier C. Military advanced regional anesthesia and analgesia handbook. Government Printing Office 2009.

[10] Scott DM. Regional anaesthesia in military medicine. Australian Defense Force Health 2008; 9: 15-7.

[11] Marhofer P, Ivani G, Suresh S, Melman E, Zaragoza G, Bosenberg A Everyday regional anesthesia in children. Paediatr Anaesth 2012; 22(10): 995-1001

[http://dx.doi.org/10.1111/pan.12003] [PMID: 22967158]

[12] Mergeay M, Verster A, Van Aken D, Vercauteren M. Editorial Regional versus general anesthesia for spine surgery. A comprehensive review. Acta An $\backslash$ a Esthesiologica Belgica 2015; 66: $1-9$.

[13] Wu CL, Fleisher LA. Outcomes research in regional anesthesia and analgesia. Anesth Analg 2000; 91(5): 1232-42. [PMID: 11049915]

[14] Horlocker TT. Peripheral nerve blocks--regional anesthesia for the new millennium. Reg Anesth Pain Med 1998; 23(3): 237-40. [http://dx.doi.org/10.1016/S1098-7339(98)90047-5] [PMID: 9613532]

[15] Cozowicz C, Poeran J, Memtsoudis SG. Epidemiology, trends, and disparities in regional anaesthesia for orthopaedic surgery. $\mathrm{Br} \mathrm{J}$ Anaesth 2015; 115(Suppl. 2): ii57-67.

[http://dx.doi.org/10.1093/bja/aev381] [PMID: 26658202]

[16] Baydar H, Duru LS, Ozkardesler S, Akan M, Meseri RD, Karka G. Evaluation of education, attitude, and practice of the Turkish anesthesiologists in regional block techniques. Anesth Pain Med 2013; 2(4): 164-9.

[http://dx.doi.org/10.5812/aapm.7632] [PMID: 24223354]

[17] Neal JM. Education in regional anesthesia: caseloads, simulation, journals, and politics: 2011 Carl Koller Lecture. Reg Anesth Pain Med 2012; 37(6): 647-51.

[http://dx.doi.org/10.1097/AAP.0b013e318267c043]

[PMID: 23086349]

[18] McDonald SB, Thompson GE. "See one, do one, teach one, have one": a novel variation on regional anesthesia training. Reg Anesth Pain 
Med 2002; 27(5): 456-9.

[http://dx.doi.org/10.1097/00115550-200209000-00003] [PMID: 12373691]

[19] Brull R, Wijayatilake DS, Perlas A, et al. Practice patterns related to block selection, nerve localization and risk disclosure: a survey of the American Society of Regional Anesthesia and Pain Medicine. Reg Anesth Pain Med 2008; 33(5): 395-403. [http://dx.doi.org/10.1097/00115550-200809000-00002]

[PMID: 18774508]

[20] Ivani G, Ferrante FM. The American Society Of Regional Anesthesia and Pain Medicine and the European Society Of Regional Anaesthesia and Pain Therapy Joint Committee recommendations for education and training in ultrasound guided regional anesthesia: why do we need these guidelines? Reg Anesth Pain Med 2009; 34(1): 8-9. [http://dx.doi.org/10.1097/AAP.0b013e3181926b3d]

[PMID:
[21] Birnbach D. The public's perception of regional anesthesia: why don't they get "the point"? Reg Anesth Pain Med 2004; 29(2): 86-9.

[http://dx.doi.org/10.1016/j.rapm.2003.12.020] [PMID: 15029540]

[22] Haile M, Desalegn N, Akalu L. Practice of regional anesthesia and analgesia in Ethiopian hospital. Int J Med Med Sci 2015; 7: 130-8. [http://dx.doi.org/10.5897/IJMMS2015.1132]

[23] Mwangi DSM. A survey of anaesthesiologists'practicing in kenya on knowledge attitude and practice towards the use of peripheral nerve blocks. 2013.

[24] Buist RJ. A survey of the practice of regional anaesthesia. J R Soc Med 1990; 83(11): 709-12.

[http://dx.doi.org/10.1177/014107689008301112] [PMID: 2250269]

[25] Hadzić A, Vloka JD, Kuroda MM, Koorn R, Birnbach DJ. The practice of peripheral nerve blocks in the United States: a national survey [p2e comments]. Reg Anesth Pain Med 1998; 23(3): 241-6. [http://dx.doi.org/10.1097/00115550-199823030-00002] [PMID: 9613533]

\section{(C) 2021 Habtu et al.}

This is an open access article distributed under the terms of the Creative Commons Attribution 4.0 International Public License (CC-BY 4.0), a copy of which is available at: https://creativecommons.org/licenses/by/4.0/legalcode. This license permits unrestricted use, distribution, and reproduction in any medium, provided the original author and source are credited. 